\title{
Sinopse das espécies nativas e subespontâneas de Andropogoneae Dumort. (Poaceae) na llha de Santa Catarina, Brasil ${ }^{1}$
}

\author{
Bárbara Toncic Neves ${ }^{1}$ e Ana Zanin ${ }^{2,3}$
}

Recebido em 15/04/2011. Aceito em 10/10/2011

\begin{abstract}
RESUMO
(Sinopse de Andropogoneae Dumort. (Poaceae) nativas e subespontâneas da Ilha de Santa Catarina, Florianópolis, SC, Brasil). O presente trabalho consiste no levantamento dos táxons da tribo Andropogoneae (Panicoideae - Poaceae) ocorrentes na Ilha de Santa Catarina, Florianópolis, Brasil. A partir da revisão de materiais de herbários e coletas a campo foi confirmada a ocorrência de 10 gêneros e 20 espécies, 17 nativas e duas subespontâneas: Andropogon L. (7 spp.), Bothriochloa Kuntze (2), Eriochrysis P. Beauv. (1), Hyparrhenia Andersson ex E. Fourn. (1), Imperata Cirillo (1), Ischaemum L. (1), Rhytachne Desv. (1), Saccharum L. (3), Schizachyrium Nees (2) e Sorghum Moench (1). Os gêneros Bothriochloa e Rhytachne são registrados pela primeira vez para a Ilha de Santa Catarina. São apresentadas chaves de identificação para gêneros e espécies, ilustrações, informações sobre distribuição geográfica, habitat, período de floração e comentários para cada táxon.
\end{abstract}

Palavras-chave: florística, Poaceae, vegetação litorânea, Ilha de Santa Catarina, Brasil

\begin{abstract}
(A synopsis of the Andropogoneae Dumort. (Poaceae) native and subspontaneous to the Island of Santa Catarina, Florianópolis, SC, Brazil). The present work is a survey of the taxa in the tribe Andropogoneae (Panicoideae - Poaceae) that occur on the Island of Santa Catarina, Florianópolis, Brazil. Based on a review of herbarium specimens and fieldwork, 20 species were recorded in the following 10 genera: Andropogon L. (7 spp.), Bothriochloa Kuntze (2), Eriochrysis P. Beauv. (1), Hyparrhenia Andersson ex E. Fourn. (1), Imperata Cirillo (1), Ischaemum L. (1), Rhytachne Desv. (1), Saccharum L. (3), Schizachyrium Nees (2) and Sorghum Moench (1). Seventeen of the species are native, and two species are subspontaneous. Bothriochloa and Rhytachne are recorded here, for the first time, for the Island of Santa Catarina. This work provides key to the genera and species, as well as illustrations, information about geographic distribution, habitat, phenology, and comments about each taxon presented in the study.
\end{abstract}

Key words: flora, grass, Poaceae, coastal vegetation, Santa Catarina Island, Brazil

\section{Introdução}

As Poaceae compreendem 793 gêneros e cerca de 10.000 espécies (Watson \& Dallwitz 1992) distribuídas especialmente em ambientes terrestres abertos. No Brasil, está representada por 204 gêneros e 1.401 espécies, sendo 20 gêneros e 458 espécies endêmicos do país (Filgueiras et al. 2010).

A família está dividida em subfamílias, sendo a proposta mais aceita na última década a do Grass Phylogeny Working Group (GPWG 2001) que reconhece 12 subfamílias estabelecidas com base na análise combinada de dados moleculares e diferentes grupos de caracteres exomorfológicos e endomorfológicos. Posteriormente, Sánchez-Ken et al. (2007) propuseram o reconhecimento de mais uma subfamília, elevando o número para 13.

A tribo Andropogoneae pertence à subfamília Panicoideae que, de acordo com Burman (1985) abrange 40,10\% dos gêneros e $61,26 \%$ das espécies de Poaceae do Brasil, sendo mais freqüente em áreas de altas temperaturas $\mathrm{e}$ pluviosidade. É uma das maiores tribos de Poaceae com 85 gêneros e 960 espécies (Clayton \& Renvoize 1986) de distribuição ampla nas regiões tropicais e subtropicais do mundo.

A tribo compreende, em sua maioria, espécies perenes, de hábito cespitoso e ciclo de vida estival que se destacam no campo especialmente por apresentarem suas inflorescências albo-plumosas. Algumas espécies constituem-se em importantes componentes de pastagens naturais nos campos

\footnotetext{
Parte da dissertação de Mestrado da primeira Autora

2 Universidade Federal de Santa Catarina, Programa de Pós-Graduação em Biologia Vegetal, Florianópolis, SC, Brasil

3 Autor para correspondência: anazanin@ccb.ufsc.br
} 
sul-brasileiros (Hervé \& Valls 1980) e também em áreas de cerrado com vegetação baixa, no Brasil Central, onde algumas espécies são utilizadas em pastagens cultivadas (Allem \& Valls 1987).

Importantes trabalhos relacionados à família Poaceae abrangendo táxons da tribo Andropogoneae ocorrentes no Brasil meridional foram realizados, destacando-se: Rosengurtt et al. (1970), Hervé \& Valls (1980), Türpe (1984), Renvoize (1984, 1998), Nicora \& Rúgulo de Agrasar (1987), Marchi \& Longhi-Wagner (1998), Vega (2000), LonghiWagner et al. (2001), Zanin (2001) e Peichoto (2010).

Este trabalho apresenta os táxons nativos e subespontâneos da tribo Andropogoneae ocorrentes na Ilha de Santa Catarina, incluindo chaves para identificação, ilustrações, dados sobre hábitat, distribuição geográfica e período de floração.

\section{Material e métodos}

A Ilha de Santa Catarina está localizada no município de Florianópolis $\left(27^{\circ} 35^{\prime} 48^{\prime \prime} \mathrm{S}-48^{\circ} 32^{\prime} 58^{\prime \prime} \mathrm{W}\right)$, no estado de Santa Catarina, na região sul do Brasil. Abrange uma área de cerca de $423 \mathrm{~km}^{2}$ com formações de Floresta Ombrófila Densa e ecossistemas associados de manguezais, vegetação de restinga, praia, dunas e floresta de planícies quaternárias, caracterizadas como formações vegetais edáficas (Caruso 1990, CECCA 1997).

O presente estudo envolveu a revisão de coleções dos Herbários FLOR, HBR, SPF e CTES (siglas conforme Thiers 2010) e coletas de material no campo realizadas mensalmente entre abril de 2009 e abril de 2010, procurando abranger todas as formações abertas da Ilha. Foram coletadas amostras de plantas férteis e herborizadas de acordo com os métodos utilizados em estudos florísticos e taxonômicos (Mori et al. 1989) e as exsicatas incorporadas no Herbário FLOR, da Universidade Federal de Santa Catarina.
A identificação das espécies foi feita com base na literatura de floras regionais, estudos revisionais e comparação com material de herbário.

Para a descrição adotou-se a terminologia apresentada por Radford et al. (1974) e Hickey \& King (2000). As descrições de cores das estruturas foram baseadas em observações feitas em campo e em material herborizado. A citação dos autores dos táxons segue Brummitt \& Powell (1992).

\section{Resultados e discussão}

\section{Andropogoneae Dumort}

Plantas perenes, às vezes anuais, cespitosas, com ou sem rizomas, menos frequentemente estoloníferas. Inflorescências formadas por unidades compostas geralmente por dois ou mais ramos floríferos, menos frequentemente um, conjugados, digitados ou subdigitados, ou em panículas, subtendidas por uma bráctea (espatéola), evidente ou não; ramos floríferos com espiguetas dispostas em pares em cada nó da ráquis, uma séssil ou subséssil e outra pedicelada, homógamas ou heterógamas, geralmente caindo em conjunto com o entrenó da ráquis, às vezes as duas espiguetas caindo separadamente, no ápice dos ramos a espigueta séssil é acompanhada de duas pediceladas. Pedicelos e entrenós da ráquis pilosos, menos comumente glabros ou escabros. Espiguetas sésseis acrótonas, bifloras, com dois antécios, geralmente bissexuadas; glumas inferiores geralmente biquilhadas; glumas superiores geralmente uniquilhadas; antécio inferior neutro ou estaminado, com 3 estames; antécio superior com flor bissexuada, com (1-)3 estames, ou raramente pistilada; lema mútico ou aristado. Cariopse oval, glabra, geralmente livre dentro do antécio. Espiguetas pediceladas reduzidas neutras, ou desenvolvidas estaminadas, às vezes bissexuadas, mais raramente pistiladas.

\section{Chave para os gêneros nativos e subespontâneos de Andropogoneae ocorrentes na llha de Santa Catarina}

1. Inflorescências em unidades com um ou mais ramos floríferos conjugados, digitados ou subdigitados, terminais ou terminais e axilares

2. Inflorescências solitárias no ápice do colmo formadas por apenas um ramo subtendido pela espatéola, esta não evidente; gluma inferior da espigueta séssil geralmente muricada ..... 7. Rhytachne rottboellioides

2. Inflorescências terminais e axilares, com um ou mais ramos floríferos por espatéola; gluma inferior da espigueta séssil nunca muricada.....

3. Plantas longo-estoloníferas, estolões vináceos com nós geralmente branco-pilosos; gluma inferior da espigueta séssil com dorso liso-lustroso na metade inferior 6. Ischaemum minus

3. Plantas cespitosas, às vezes com rizomas curtos, nós glabros, raramente pubescentes; gluma inferior da espigueta séssil sem as características acima.

4. Inflorescências em unidades com 2(-3) ramos floríferos por espatéola, com pilosidade rufa evidente; tricomas rufos presentes nos pedicelos, entrenós da ráquis, glumas inferiores das espiguetas séssil e pedicelada 4. Hypahrrenia rufa

4. Inflorescências em unidades com um ou mais ramos floríferos por espatéola, glabras ou branco-plumosas 
5. Inflorescências em unidades com um ramo florífero subtendido pela espatéola, leve a densamente brancoplumosas; espiguetas sésseis com gluma inferior convexa, bissexuadas; espigueta pedicelada sempre reduzida e neutra

9. Schizachyrium

5. Inflorescências em unidades geralmente com dois ou mais ramos floríferos por espatéola, raro um (na Ilha de Santa Catarina Andropogon virgatus); espiguetas sésseis com gluma inferior plana ou côncava, bissexuadas, raro pistiladas (A. virgatus); espigueta pedicelada reduzida ou desenvolvida

1. Andropogon

1. Inflorescências em panícula laxa, contraída ou subcontraída, com ramos distribuídos sobre um eixo central persistente e alongado

6. Panículas contraídas ou subcontraídas, geralmente densamente branco-plumosas

7. Pedicelos e entrenós da ráquis com sulco hialino longitudinalmente

2. Bothriochloa

7. Pedicelos e entrenós da ráquis sem sulco longitudinalmente

8. Espiguetas aristadas, glabras ou pilosas, uma séssil e outra pedicelada, pedicelo e entrenós caindo junto com a espigueta séssil, espigueta pedicelada caindo separadamente

8. Saccharum

8. Espiguetas múticas, densamente pilosas, ambas pediceladas, caindo isoladamente; pedicelos e entrenós da ráquis persistentes

5. Imperata brasiliensis

6. Panículas laxas, esparsamente pilosas, ou contraídas, então com pilosidade castanho-dourada geralmente encobrindo as espiguetas

9. Panícula contraída, com pilosidade castanho-dourada geralmente encobrindo as espiguetas; espiguetas pediceladas desenvolvidas com flor pistilada 3. Eriochrysis cayennensis

9. Panícula laxa, escabra ou esparsamente curto-pilosa, com tricomas hialinos; espiguetas pediceladas desenvolvidas com flor estaminada, às vezes neutras

10. Sorghum halepense

1. Andropogon L., Sp. pl. 1: 1045. 1753. Diectomis Kunth, Mém. Mus. Hist. Nat. Paris, 2. 69: 1815, nom. cons., non P. Beauv. 1812 Hypogynium Nees, Agrostologia brasiliensis, in Mart., Fl. bras. enum. pl. 2(1): 364. 1829.

Gênero com cerca de 100 espécies, predominando nas regiões tropicais e subtropicais (Zanin 2001; Zanin \& Longhi-Wagner 2006). No continente americano está mais bem representado na América do Sul, especialmente no Brasil, onde são reconhecidas 28 espécies, uma subespécie e uma variedade, sendo uma espécie introduzida da África (Zanin 2010a). Na Ilha de Santa Catarina o gênero está representado por sete espécies, todas nativas, sendo Andropogon lateralis representado pela subespécie típica.

\section{Chave de identificação dos táxons de Andropogon ocorrentes na llha de Santa Catarina}

1. Inflorescência com um ramo florífero por espatéola; espiguetas sésseis pistiladas

1. Inflorescência com dois ou mais ramos floríferos por espatéola; espiguetas sésseis bissexuadas

2

2. Inflorescências corimbiformes, congestas no ápice dos colmos floríferos; espiguetas pediceladas reduzidas e neutras ao longo dos ramos floríferos e uma reduzida e outra desenvolvida e estaminada no ápice dos mesmos, raro ambas reduzidas ou desenvolvidas

2. Inflorescências não corimbiformes, laxas, alongadas, geralmente distribuída na metade superior dos colmos floríferos; espiguetas pediceladas sempre reduzidas e neutras ou reduzidas e desenvolvidas estaminadas, raro desenvolvida neutra na mesma planta

3. Espiguetas pediceladas sempre reduzidas e neutras ao longo e no ápice dos ramos

4. Espiguetas sésseis com aristas conspícuas, de 20-31 mm compr. 5. A. macrothrix

4. Espiguetas sésseis múticas ou com aristas de 1-4 mm compr.

5. Lâmina foliar de ápice obtuso-navicular; espiguetas sésseis 3,2-5 mm compr., quilhas da gluma inferior com nervuras conspícuas 6. A. selloanus

5. Lâmina foliar de ápice agudo; espiguetas sésseis 2,5-3,2(-3,8) mm compr., quilhas da gluma inferior com nervuras inconspícuas

3. Espiguetas pediceladas sempre estaminadas ou estaminadas e neutras ao longo e no ápice dos ramos .. 6

6. Inflorescências densamente branco-plumosas; tricomas dos pedicelos e entrenós da ráquis 3-4 vezes o comprimento da espigueta séssil; plantas exclusivamente de solos arenosos de restinga

1. A. arenarius

6. Inflorescências esparsamente pilosas; tricomas dos pedicelos e entrenós da ráquis geralmente mais curtos que a espigueta séssil, às vezes ligeiramente maior; plantas de outros ambientes, geralmente de solo úmido, eventualmente alcançando margens de restingas 3. A. lateralis subsp. lateralis 
1.1 Andropogon arenarius Hack., Flora 68 (8): 134. 1885. Andropogon arenarius Hack. f. subcompletus Hack. in Lindm., Kongl. Svenska Vetenskapsakad. Handl. 346: 6. 1900.

Fig. 1 A-B

Ocorre no Uruguai e região Sul do Brasil, diminuindo em direção norte, onde tem registros apenas para a Ilha do Mel no Paraná e na Ilha do Cardoso em São Paulo (Zanin 2001, 2010a). É característica e exclusiva dos solos arenosos e secos de restinga, ocorrendo na Ilha de Santa Catarina sobre dunas secundárias e frontais e nas planícies entre as dunas frontais e internas.

A espécie caracteriza-se por apresentar grandes populações com vistosas touceiras e longos e densos tricomas brancos nos pedicelos e entrenós da ráquis, com 3-4 vezes o comprimento da espigueta séssil. Possui espiguetas pediceladas estaminadas e neutras na mesma planta. Coletada com flor e/ou fruto de setembro a março.

Material selecionado: BRASIL. Santa Catarina: Florianópolis, Ingleses, 11/V/2009, B. Toncic \& A. Zanin 228 (FLOR).

\subsection{Andropogon bicornis L., Sp. pl. 1046. 1753.} Fig.1 C-E

Distribui-se desde a Argentina até o México (Renvoize 1998; Zanin 2001). No Brasil ocorre em quase todos os Estados não tendo sido registrada apenas no Rio Grande do Norte (Zanin 2010a). Na Ilha de Santa Catarina a espécie está associada a solos arenosos, geralmente úmidos, em baixadas entre dunas, em campos antropizados e planícies em geral.

Andropogon bicornis diferencia-se das demais espécies do gênero encontradas na Ilha por apresentar inflorescências densamente plumosas, corimbiformes e congestas no ápice dos colmos floríferos, com a comum presença de pelo menos uma espigueta estaminada pedicelada de coloração castanho-vinácea no ápice dos ramos floríferos, contrastando com a pilosidade branca dos ramos. Raramente foi observada a presença de uma espigueta pedicelada bissexuada no ápice do ramo florífero, bem como espigueta séssil com arista desenvolvida de $1,5 \mathrm{~mm}$ de comprimento e colmo com o desenvolvimento de um pequeno rizoma, de aproximadamente $2 \mathrm{~cm}$ de comprimento, características não referidas para A. bicornis. Coletada com flor e/ou fruto de novembro a julho.

Material selecionado: BRASIL. Santa Catarina: Florianópolis, Campeche, 16/XI/2009, B. Toncic \& A. Zanin 254 (FLOR).

1.3 Andropogon lateralis Nees subsp. lateralis, Agrostologia brasiliensis, in Mart., Fl. bras. enum. pl. 2(1): 329. 1829. Andropogon incanus Hack., in A. DC.\& DC., Monogr. phan. 6: 431. 1889.

Fig. 1 F-G
Distribui-se no Equador, Colômbia, Argentina, Paraguai, Uruguai e Brasil (Zanin 2001; Morrone et al. 2008). No Brasil está presente nas regiões Sudeste, Centro-Oeste e Sul, mas especialmente nos campos sulinos (Zanin 2001, 2010a). Na Ilha de Santa Catarina foi recoletada no presente estudo após os últimos registros da década de 1960, sempre associada a ambientes de campos litorâneos remanescentes na Ilha, especialmente em baixadas úmidas, alcançando eventualmente margens de restingas. Andropogon lateralis possui duas subespécies, A. lateralis subsp. lateralis e A. lateralis subsp. cryptopus (Trin. ex Hack.) A. Zanin, sendo somente a primeira encontrada na região sul do Brasil (Zanin 2006, 2010a).

Andropogon lateralis subsp. lateralis caracteriza-se especialmente por apresentar 2-4 ramos floríferos não ramificados por espatéola, iguais ou subiguais no comprimento, tricomas da ráquis e do pedicelo subdensos e geralmente mais curtos que as espiguetas sésseis, estas sempre com aristas geniculadas de 4-9 $\mathrm{mm}$ de comprimento. Coletada com flor e/ou fruto de outubro a fevereiro.

Material selecionado: BRASIL. Santa Catarina: Florianópolis, Carianos, 16/XI/2009, B. Toncic \& A. Zanin 262, 263 (FLOR).

1.4 Andropogon leucostachyus Kunth in Humb., Bonpl. \& Kunth, Nov. gen. sp. 1: 187. 1816.

Fig. $1 \mathrm{H}-\mathrm{I}$

Encontrada nas Américas Central e do Sul (Zanin 2001; Clayton et al. 2006). No Brasil distribui-se em todas as Regiões (Zanin 2010a). Na Ilha de Santa Catarina ocorre em diversos ambientes como solos descobertos, pedregosos ou não, campos litorâneos e ambientes alterados em geral, tanto em solo seco quanto úmido. Andropogon leucostachyus caracteriza-se por apresentar inflorescências albo-plumosas e delicadas, com os tricomas dos pedicelos e dos entrenós da ráquis 3-4 vezes o comprimento da espigueta séssil assemelhando-se a $A$. selloanus, com a qual muitas vezes é confundida em campo. Entretanto, distingui-se desta por apresentar inflorescências mais delicadas, espiguetas sésseis aristadas e geralmente menores e lâminas foliares mais longas e estreitas, com ápice agudo, enquanto em $A$. selloanus em geral as folhas são mais largas e com ápice obtuso-navicular e as espiguetas sésseis maiores e geralmente múticas. Coletada com flor e/ou fruto durante todo o ano.

Material selecionado: BRASIL. Santa Catarina: Florianópolis, Pântano do Sul, 23/XI/2009, B. Toncic \& A. Zanin 285 (FLOR).

1.5 Andropogon macrothrix Trin., Mém. Acad. Imp. Sci. Saint-Pétersbourg ser. 6 Sci. Math. Nat. 2: 270. 1832. Andropogon ternatus (Spreng.) Nees subsp. macrothrix

(Trin.) Hack. in Mart. \& Eichler, Fl. bras. 2 (3): 289. 1883. Fig. $1 \mathrm{~J}-\mathrm{K}$

Ocorre no Paraguai, Uruguai, Argentina, Brasil (Morrone et al. 2008) e Bolívia (Renvoize 1998). No Brasil ocorre 
nas regiões Nordeste, Centro-Oeste, Sudeste e Sul, com predomínio na região Sul (Zanin 2010a). Citada pela primeira vez para a Ilha de Santa Catarina, onde foi encontrada formando esparsa população em baixada úmida com solo arenoso em remanescente de campo litorâneo. Apresenta poucos registros para o litoral do Estado, sendo mais conhecida dos campos de altitude com elevada umidade em Santa Catarina (Zanin 2001).

Andropogon macrothrix caracteriza-se por apresentar inflorescências vistosas, branco-plumosas, terminais ou terminais e axilares, com até 9 ramos floríferos por espatéola e espiguetas sésseis com aristas longas alcançando $20-31 \mathrm{~mm}$ de comprimento. Coletada com flor no mês de novembro.

Material examinado: BRASIL. Santa Catarina: Florianópolis, Campeche, 16/XI/2009, B. Toncic \& A. Zanin 255, 259 (FLOR).

1.6 Andropogon selloanus (Hack.) Hack., Bull. Herb. Boissier. 2(4): 266. 1904. Andropogon leucostachyus Kunth subsp. selloanus Hack. in A. DC. \& DC. Monogr. phan. 6: 420.1889.

Fig. 1 L-M

Ocorre nas Américas Central e do Sul, distribuindose desde o México e Antilhas até a Argentina (Zanin \& Longhi-Wagner 2006; Clayton et al. 2006). No Brasil ocorre em quase todo o país, sem registro confirmado apenas para Acre, Amapá e Rondônia (Zanin 2001, 2010a). Na Ilha de Santa Catarina está geralmente associada a solos arenosos secos entre dunas e também em locais úmidos, próximo às margens de lagoas e em baixadas úmidas.

Andropogon selloanus caracteriza-se por apresentar inflorescências densamente albo-plumosas e plantas geralmente de pequeno porte. Espécie semelhante à Andropogon leucostachyus, diferenciando-se por suas espiguetas sésseis múticas e maiores, com nervuras nas quilhas das glumas bem marcadas e lâminas foliares mais curtas e largas, com ápice obtuso-navicular. Coletada com flor e/ou fruto durante todo o ano.

Material selecionado: BRASIL. Santa Catarina: Florianópolis, Praia do Gravatá, 02/II/2010, B. Toncic \& A. S. Mello 323 (FLOR).

1.7 Andropogon virgatus Desv. in Ham., Prodr. Pl. Ind. Occid.: 9. 1825. Hypogynium virgatum (Desv.) Dandy, J. Bot. 69(2): 54. 1931.

Fig. $1 \mathrm{~N}-\mathrm{O}$

Ocorre do México até a Argentina, Paraguai, Uruguai e Brasil (Zanin 2006; Morrone et al. 2008). No Brasil distribui-se em todas as Regiões (Zanin 2010a). Espécie com poucos registros para Ilha de Santa Catarina, da década de 1960, e recoletada no presente estudo, sempre associada a solos úmidos e brejosos dos remanescentes de campos litorâneos, e em beira de riacho.

Andropogon virgatus apresenta inflorescências congestas e estreitas com apenas um ramo florífero por espatéola, pedicelos e entrenós da ráquis escabros e espigueta séssil pistilada, características que a diferenciam de todas as outras espécies de Andropogon ocorrentes na Ilha de Santa Catarina, que apresentam mais de um ramo florífero por espatéola, inflorescências plumosas e espigueta séssil bissexuada. Coletada com flor e/ou fruto de outubro a janeiro.

Material selecionado: BRASIL. Santa Catarina: Florianópolis, Jurerê, 28/I/2010, B. Toncic \& A. Zanin 302 (FLOR).

2. Bothriochloa Kuntze, Revis. Gen. Pl. 2: 762. 1891.

Gênero com cerca de 35 espécies de regiões tropicais e subtropicais (Clayton \& Renvoize 1986; Renvoize 1998; Vega 2000). Para o Brasil são referidas 11 espécies e duas variedades (Valls 2010).

$\mathrm{Na}$ Ilha de Santa Catarina ocorrem duas espécies.

\section{Chave de identificação dos táxons de Bothriochloa ocorrentes na llha de Santa Catarina}

1. Espiguetas sésseis múticas; lema superior ausente

1. Espiguetas sésseis aristadas; lema superior presente 2. B. laguroides var. laguroides

2.1 Bothriochloa exaristata (Nash) Henrard, Blumea 4(3): 520. 1941. Amphilophis exaristatus Nash in Small, Fl. S.E. U.S.: 65.1903.

Fig. 2 A-B

Ocorre nos Estados Unidos, Bolívia, Argentina, Paraguai e Brasil: Mato Grosso do Sul, Minas Gerais, Rio Grande do Sul e Santa Catarina (Marchi \& Longhi-Wagner 1998; Flores 2001a; Valls 2010).

Bothriochloa exaristata foi coletada pela primeira vez na Ilha de Santa Catarina durante os trabalhos de campo deste estudo. Foi encontrada em áreas alteradas com solos compactos e pedregosos em locais muito urbanizados no centro da cidade, e também em áreas rurais no interior da Ilha.

A espécie é reconhecida pela presença de espiguetas sésseis múticas e lema superior ausente. Apresenta plantas mais altas, com folhas caulinares de lâminas foliares mais longas do que Bothriochloa. laguroides, também encontrada na Ilha. Coletada com flor e/ou fruto durante todo o ano.

Material selecionado: BRASIL. Santa Catarina: Florianópolis, Carvoeira, 16/XI/2009, B. Toncic \& A. Zanin 250 (FLOR).

2.2 Bothriochloa laguroides (DC) Herter var. laguroides, Revista Sudamer. Bot. 6(5-6): 135. 1940. Andropogon laguroides DC., Catal. Plant. Hort. Monspel. 78. 1813.

Fig. 2 C-D

Ocorre no México, Guatemala, Honduras, Panamá, Paraguai, Uruguai, Argentina e Brasil (Marchi \& LonghiWagner 1998). No Brasil há registro para Rio de Janeiro, São Paulo, Rio Grande do Sul e Santa Catarina (Flores 

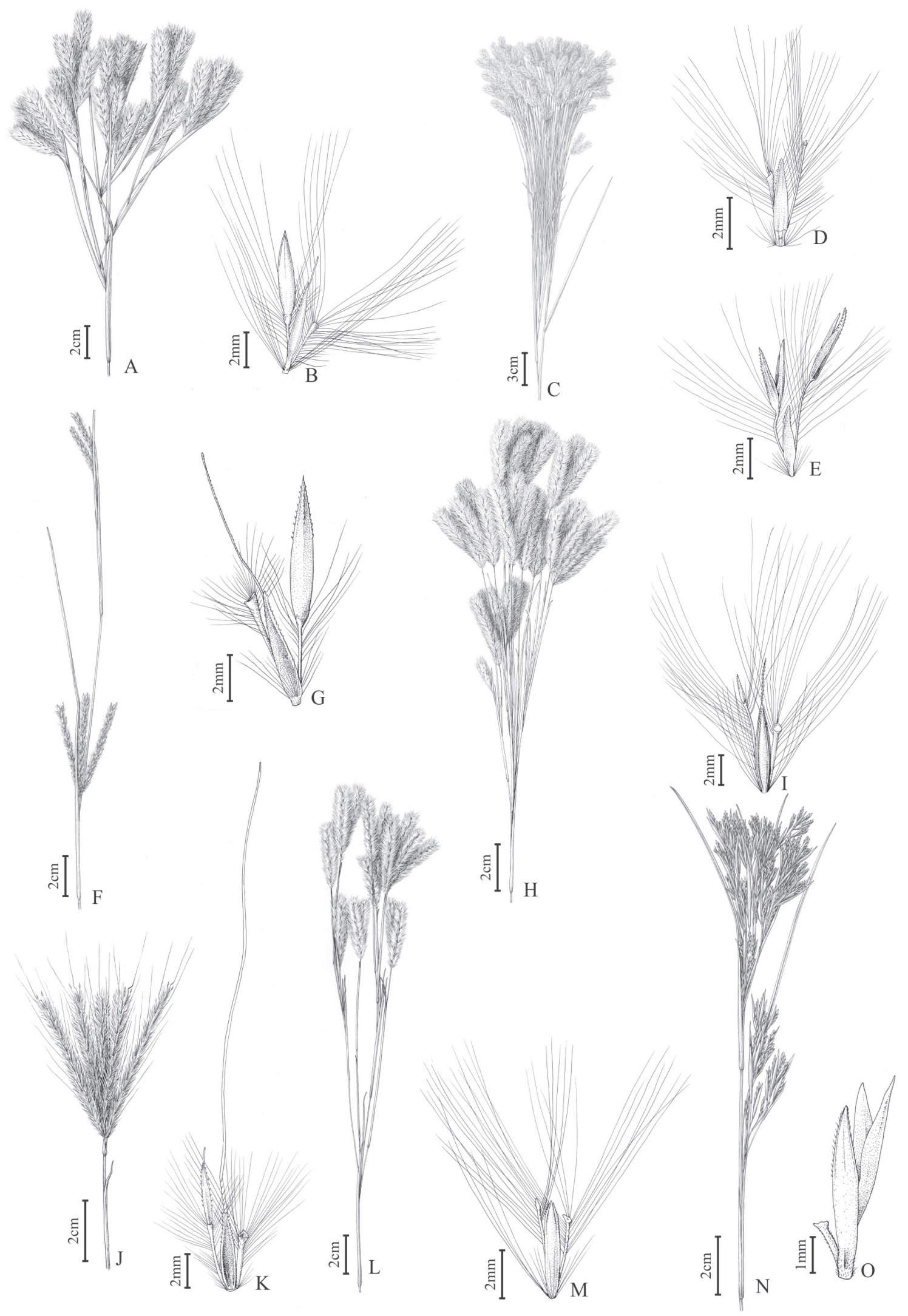

Figura 1. A-B. Andropogon arenarius. A. inflorescência, B. par de espiguetas (B. Toncic \& A. Zanin 249); C-E. A. bicornis. C. inflorescência, D. par de espiguetas, E. diásporo terminal (B. Toncic \& A. Zanin 235); F-G. A. lateralis subsp. lateralis. F. inflorescência, G. par de espiguetas (Toncic \& A. Zanin 263); H-I. A. leucostachyus. H. inflorescência, I. par de espiguetas (B. Toncic \& A. Zanin 246); J-K. A. macrothrix. J. inflorescência, K. par de espiguetas (B. Toncic \& A. Zanin 259); L-M. A. selloanus. L. inflorescência, M. par de espiguetas (B. Toncic \& A. S. Mello 323); N-O. A. virgatus. N. inflorescência, O. par de espiguetas (B. Toncic \& A. Zanin 302). 
2001a; Valls 2010). É citado como o táxon de Bothriochloa mais comum no Rio Grande do Sul, ocorrendo com menor frequência em Santa Catarina (Marchi \& Longhi-Wagner 1998). Foi coletado pela primeira vez na Ilha de Santa Catarina durante este estudo, ocorrendo especialmente em ambientes alterados de áreas urbanas como estacionamentos e margens de rodovias.

Bothriochloa laguroides var. laguroides diferencia-se de B. exaristata, especialmente por possuir espiguetas sésseis aristadas com lema superior presente. Além disso, as plantas, em geral, são de menor porte, com folhas mais longas e mais concentradas na base dos colmos. Coletada com flor e/ou fruto nos meses de maio e outubro.

Material selecionado: BRASIL. Santa Catarina: Florianópolis, Beira-Mar Norte, 26/X/2009, B. Toncic \& A. Zanin 247 (FLOR).

\section{Eriochrysis P. Beauv. Ess. Agrostogr. 8. 1812.}

Gênero com cerca de sete a 10 espécies das regiões tropicais da América, África e Ásia (Clayton \& Renvoize 1982). Para a América do Sul são referidas cinco espécies (Nicora \& Rúgolo de Agrasar 1987) e para o Brasil também cinco, todas nativas (Filgueiras 2010a). Na Ilha de Santa Catarina o gênero está representado por uma espécie.

3.1 Eriochrysis cayennensis P. Beauv., Ess. Agrostogr. 8, pl. 4, f. 11. 1812.

Fig. 2 E-F

Ocorre no México e Antilhas até Argentina (Filgueiras \& Lerina 2001a). No Brasil distribui-se de Minas Gerais até o Rio Grande do Sul (Smith et al. 1982). É uma espécie pouco comum na Ilha de Santa Catarina, estando associada preferencialmente a solos úmidos de baixadas entre dunas, campos litorâneos e encostas onde escorre água das chuvas.

Eriochrysis cayennensis é reconhecida por suas inflorescências em panículas contraídas, cilíndricas, de cor castanho-dourada devido à coloração dos tricomas das espiguetas, dos entrenós da ráquis e pedicelos, além do ápice da gluma inferior da espigueta séssil truncado e trilobado, menos frequentemente tendendo a inteiro e agudo na mesma planta. Dentre as espécies de Andropogoneae ocorrentes na Ilha, apenas E. caynnensis apresenta espiguetas pediceladas com flor pistilada, sendo esta uma importante característica para diferenciá-la dos outros gêneros. Coletada com flor e/ ou fruto em dezembro.

Material selecionado: BRASIL. Santa Catarina: Florianópolis, Lagoinha do Leste, 12/XII/2009, A. Zanin, B. H. Santos \& M. Amaral 1594, 1595 (FLOR).

\section{Hyparrhenia Andersson ex E. Fourn., Mexic. Pl. 2: 51,} 67. 1886.

Gênero com cerca de 55 espécies, predominantemente africanas (Clayton \& Renvoize 1986; Renvoize 1998). No Brasil, distribui-se em todas as Regiões, onde está representado por quatro espécies, uma nativa e três subespontâneas
Filgueiras (2010b). Na Ilha de Santa Catarina está representado por uma espécie.

4.1 Hyparrhenia rufa (Nees) Stapf in Oliv., Fl. Trop. Afr. 9(2): 304-307. 1919. Trachypogon rufus Nees, Agrost. Bras. in Martius, Fl. Bras. Enum. Pl. 2(1): 345. 1829.

Fig. 2 G-H

Espécie africana e naturalizada nos trópicos do mundo, sendo introduzida no Brasil possivelmente com o comércio de escravos (Longhi-Wagner 2001a). Na Ilha de Santa Catarina, cresce espontaneamente em ambientes alterados como barrancos e gramados, formando neste último, populações densas, cobrindo todo o solo.

Hyparrhenia rufa apresenta inflorescências castanhoavermelhadas devido à pilosidade rufa dos ramos floríferos e colmos de coloração amarela e verde, às vezes também vináceos na região nodal. Coletada com flor e/ou fruto de maio a agosto.

Material selecionado: BRASIL. Santa Catarina: Florianópolis, Morro da Cruz, 04/V/2009, B. Toncic \& A. Zanin 210, 212 (FLOR).

\section{Imperata Cirillo, Pl. Rar. Neapol. 2: 26. 1792.}

Gênero com nove espécies, a maioria americanas (Flores 2001b), distribuídas nos trópicos e estendendo-se as regiões temperadas (Clayton \& Renvoize 1982, 1986). No Brasil o gênero está representado por quatro espécies distribuídas nas Regiões Nordeste, Centro-Oeste, Sudeste (Filgueiras 2010c) e Sul, onde ocorrem três espécies, Imperata brasiliensis Trin., I. contracta (Kunth) Hitchc. e I. tenuis Hakc. (Smith et al. 1982; Rambo 1984; Renvoize 1988; Morrone et al. 2008). Na Ilha de Santa Catarina ocorre uma espécie.

5.1 Imperata brasiliensis Trin., Mém. Acad. Imp. Sci. St.Pétersbourg, Sér. 6, Sci. Math. 2(3): 331. 1832.

Fig. 2 I-J

Referida para o Sul dos Estados Unidos e México, América Central, Antilhas e América do Sul (Flores 2001b). No Brasil, ocorre no Nordeste, Centro-Oeste, Sudeste (Filgueiras 2010c) e Sul (Smith et al. 1982; Renvoize 1988; Morrone et al. 2008). Na Ilha de Santa Catarina desenvolve-se preferencialmente em solos arenosos de restinga, especialmente nas baixadas alagadas entre dunas, porém também em solos mais drenados do mesmo ambiente.

Destaca-se por apresentar plantas rizomatosas com inflorescências terminais densamente plumosas, com tricomas alvos e brilhantes alcançando até $12 \mathrm{~mm}$ de comprimento e folhas rijas e resistentes. Dentre as demais espécies da tribo ocorrentes na Ilha, Imperata brasiliensis é a única que apresenta as duas espiguetas do par pediceladas, ambas bissexuadas. Coletada com flor e/ou fruto durante todo o ano.

Material selecionado: BRASIL. Santa Catarina: Florianópolis, Pântano do Sul, 23/XI/2009, B. Toncic \& A. Zanin 286 (FLOR). 
6. Ischaemum L., Sp. Pl. 2: 1049. 1753.

Gênero com cerca de 65 espécies de regiões tropicais e subtropicais, com o centro de diversidade no sul da Ásia (Flores 2001c, Clayton et al. 2006). Para o Brasil são referidas cinco espécies, quatro subespontâneas e uma nativa, Ischaemum minus (Filgueiras 2010d). Na Ilha de Santa Catarina o gênero está representado por uma espécie.

6.1 Ischaemum minus J. Presl in C. Presl, Reliq. Haenk. 1: 329. 1830.

Fig. 2 K-L

Referida para a Ásia Temperada e Ásia Oriental (Clayton et al. 2006), Uruguai, Argentina e Brasil: São Paulo, Paraná, Santa Catarina e Rio Grande do Sul (Flores 2001c; Filgueiras 2010d). Na Ilha de Santa Catarina é amplamente distribuída em áreas abertas em geral, especialmente em locais úmidos como gramados próximos a lagoas e solo arenoso úmido de restinga ou brejoso do litoral.

Ischaemum minus caracteriza-se por apresentar o hábito longo-estolonífero, com estolões de coloração vinácea e espiguetas sésseis e pediceladas com suas glumas lisas e lustrosas na região dorsal inferior, esta última característica a diferencia de Ischaemum rugosum, que ocorre em outras regiões brasileiras e que apresenta gluma inferior da espigueta séssil transversalmente rugosa no dorso. Coletada com flor e/ou fruto de setembro a fevereiro.

Material selecionado: BRASIL. Santa Catarina: Florianópolis, Ratones, 25/XI/2009, B. Toncic \& A. Zanin 291 (FLOR).

7. Rhytachne Desv. in Ham., Prodr. Pl. Ind. Occid. 11. 1825.

Gênero com cerca de 12 espécies da África e América Tropical (Clayton \& Renvoize 1986; Renvoize 1998). No Brasil ocorrem três espécies distribuídas nas regiões Norte, Sudeste (Filgueiras 2010e) e Sul (Smith et al. 1982; Morrone et al. 2008). Na Ilha de Santa Catarina ocorre uma espécie.

7.1 Rhytachne rottboellioides Desv. in Ham., Prodr. Pl. Ind. Occid. 12. 1825.

Fig. $2 \mathrm{M}-\mathrm{O}$

Com ocorrência na África Tropical, Américas Central e do Sul (Renvoize 1998; Longhi-Wagner 2001b). No Brasil ocorre em Minas Gerais (Filgueiras 2010e) e no Sul (Smith et al. 1982; Morrone et al. 2008). Na Ilha de Santa Catarina os poucos registros são especialmente de campos litorâneos muito úmidos ou banhados.

Caracteriza-se por sua inflorescência com um ramo florífero solitário longo, de 10-30 cm de comprimento no ápice do colmo, lâminas foliares rijas convoluto-filiformes e espiguetas sésseis geralmente muricadas a lisas. Pode apresentar na mesma inflorescência espiguetas pediceladas reduzidas e neutras ou desenvolvidas e bissexuadas, semelhantes às sésseis, porém com gluma superior cartácea e não membranácea como nas sésseis. Coletada com flor e/ ou fruto de setembro a novembro.
Material selecionado: BRASIL. Santa Catarina: Florianópolis, Rio Tavares, 19/XI/2009, B. Toncic \& A. S. Mello 269 (FLOR).

8. Saccharum L., Sp. Pl. 1: 54. 1753.

Erianthus Michx., Fl. Bor. Amer. 1: 54. 1803.

O gênero Saccharum sensu lato compreende cerca de 25 espécies distribuídas nos trópicos e subtrópicos do mundo (Filgueiras \& Lerina 2001b). No Brasil está presente em praticamente todas as Regiões, representado por três espécies nativas e uma subespontânea (Filgueiras 2010f). Na Ilha de Santa Catarina ocorrem três espécies.

\section{Chave de identificação das espécies de Saccharum ocorrentes na llha de Santa Catarina}

1. Espiguetas sésseis glabras 1. S. asperum

1. Espiguetas sésseis glabras e pilosas na mesma inflorescência ou densamente pilosas 2

2. Glumas inferiores glabras ou pilosas na mesma planta; inflorescências geralmente exsertas; estames com anteras de 1-2 mm compr. 2. S. angustifolium

2. Glumas inferiores densamente pilosas; inflorescências geralmente inclusas lateralmente na espatéola; estames com anteras de 0,7-1 mm compr. 3. S. villosum

8.1 Saccharum angustifolium (Nees) Trin., Mém. Acad. Imp. Sci. Saint-Pétersbourg, Sér. 6, Sci. Math., Seconde Pt. Sci. Nat. 4: 92. 1836. Erianthus angustifolius Nees, Agrost. Bras. in Martius, Fl. Bras. Enum. Pl. 2(1): 316317. 1829. Erianthus biaristatus (Hack.) Swallen, Phytologia 14(2): 92. 1966.

Fig. 3 A-C

Ocorre na Venezuela, Colômbia, Bolívia, Uruguai e Argentina (Renvoize 1998; Clayton et al. 2006; Morrone et al. 2008) e no Brasil, especialmente na região Sul (Morrone et al. 2008; Filgueiras 2010f). Na Ilha de Santa Catarina é pouco frequente, com indivíduos esparsos ocorrendo preferencialmente nas encostas úmidas e áreas alteradas em geral.

Espécie reconhecida especialmente por apresentar inflorescências em panícula sub-contraída, de até $31 \mathrm{~cm}$ de comprimento, branco-plumosas, geralmente exsertas da espatéola. Foram observadas espiguetas sésseis glabras a pilosas na mesma inflorescência e o desenvolvimento de duas aristas tanto nas espiguetas sésseis como nas pediceladas. Coletada com flor e/ou fruto em novembro e março.

Material selecionado: BRASIL. Santa Catarina: Florianópolis, Ribeirão da Ilha, Morro do Ribeirão, 23/XI/2009, B. Toncic \& A. Zanin 278, 279 (FLOR).

8.2 Saccharum asperum (Nees) Steud., Syn. Pl. Glumac. 1: 407. 1854. Erianthus asper Nees, Agrost. Bras. in Martius, Fl. Bras. Enum. Pl. 2(1): 315-316. 1829.

Fig. 3 D-E 

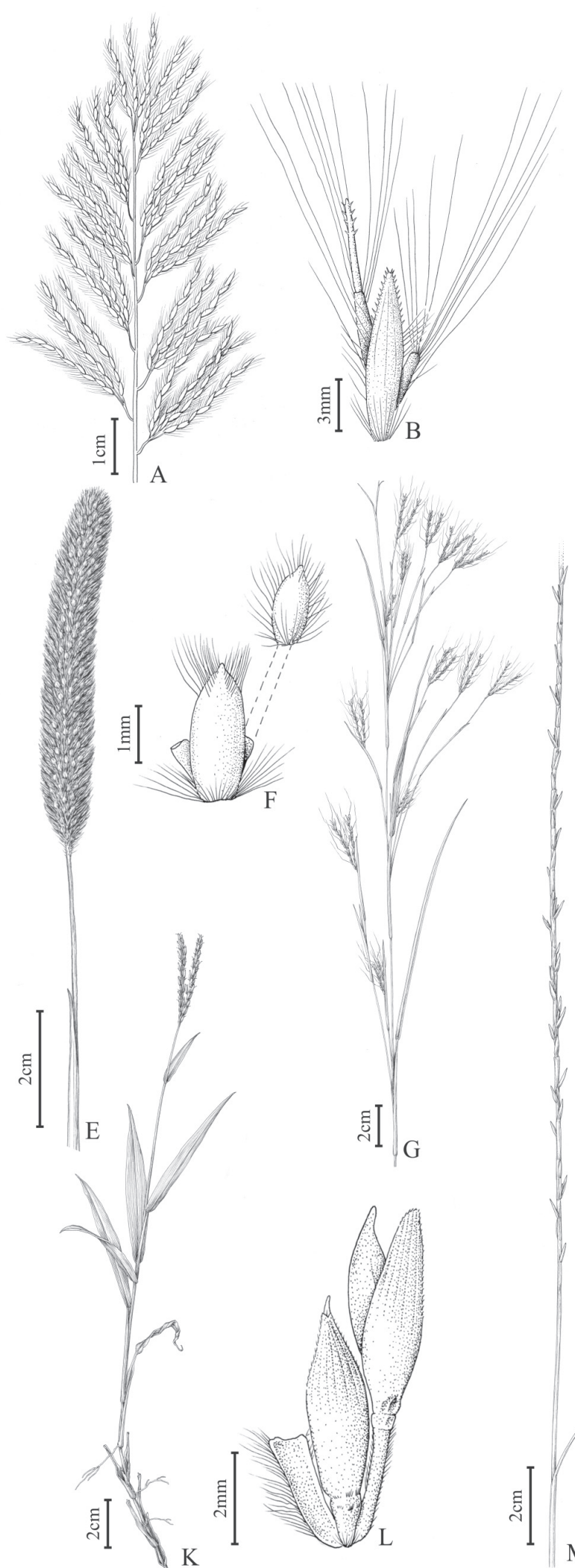

$\mathrm{K}$

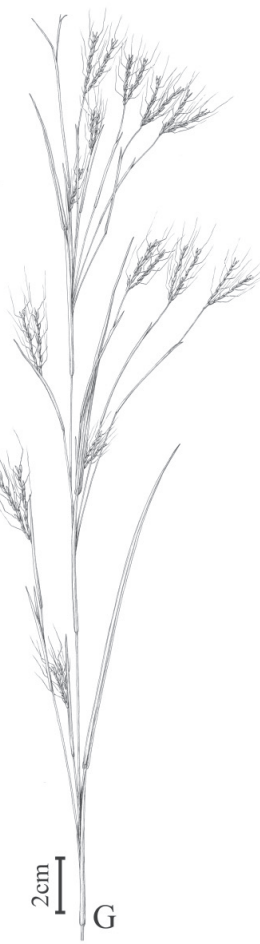

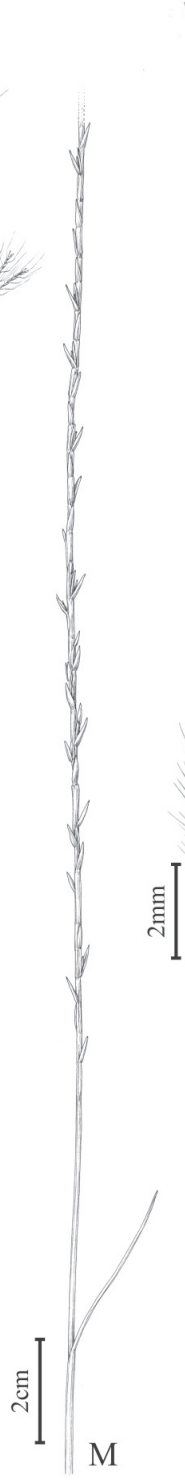
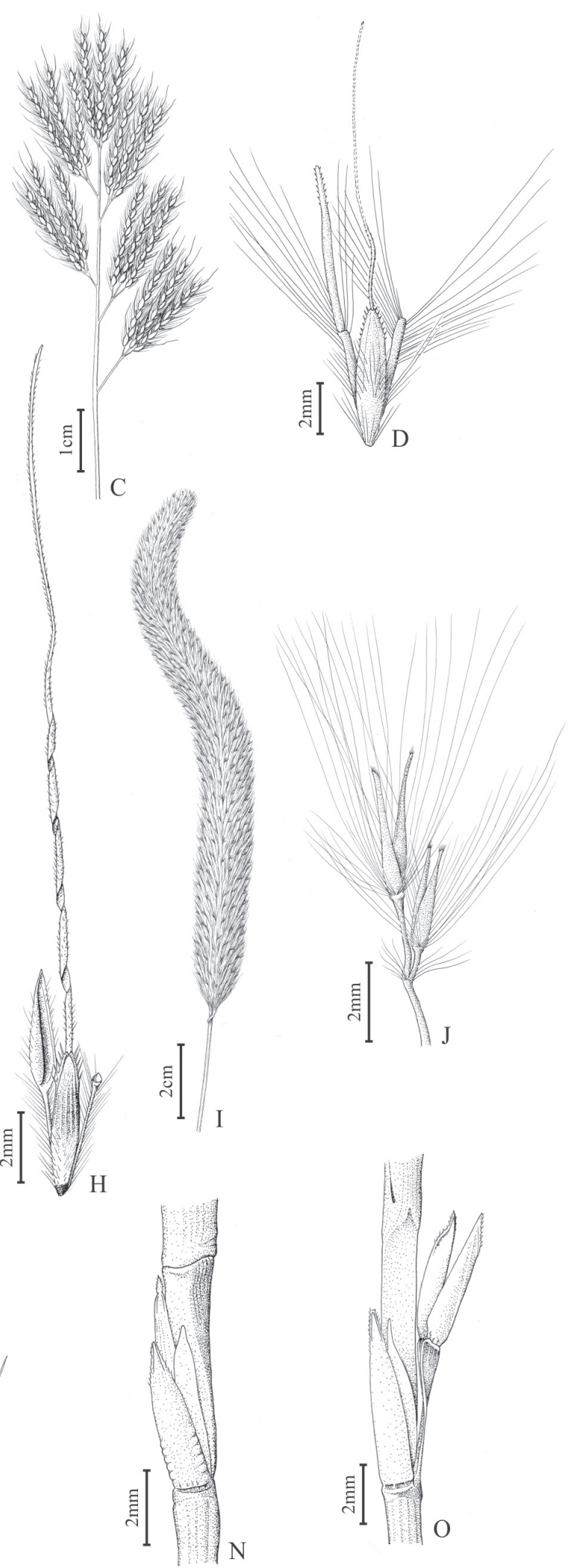

Figura 2. A-B. Bothriochloa exaristata. A. inflorescência, B. par de espiguetas (B. Toncic \& A. Zanin 232); C-D. B. laguroides var. laguroides. C. inflorescência, D. par de espiguetas (B. Toncic \& A. Zanin 205); E-F. Eriochrysis cayennensis. E. inflorescência, F. par de espiguetas (A. Zanin et al.1594); G-H. Hyparrhenia rufa. G. inflorescência, H. par de espiguetas (B. Toncic \& A. Zanin 241); I-J. Imperata brasiliensis. I. inflorescência, J. par de espiguetas (B. Toncic \& A. Zanin 286); K-L. Ischaemum minus. K. Inflorescência, L. par de espiguetas (B. Toncic \& A. Zanin 284); M-O. Rhytachne rottboellioides. M. Inflorescência, N. par de espiguetas com a pedicelada reduzida, O. par de espiguetas com a pedicelada desenvolvida (B. Toncic \& A. S. Mello 269). 
Encontrada na Argentina, Paraguai, Uruguai, Venezuela e Brasil (Filgueiras \& Lerina 2001b, Morrone et al. 2008). No Brasil é referida para Goiás, Minas Gerais até Rio Grande do Sul (Smith et al. 1982; Filgueiras 2010f). Para a Ilha de Santa Catarina há apenas quatro registros de Saccharum asperum, ocorrendo preferencialmente em ambientes úmidos e brejosos em beiras de estrada.

Saccharum asperum caracteriza-se especialmente por apresentar o par de espiguetas glabras, com glumas escabras e ápice do lema superior inteiro, não bidentado. Suas inflorescências podem ser róseas a esbranquiçadas e geralmente livres da espatéola. Coletada com flor e/ou fruto em agosto e de outubro a fevereiro.

Material selecionado: BRASIL. Santa Catarina: Florianópolis, Daniela, 16/VIII/2010, A. Zanin 1609 (FLOR).

8.3 Saccharum villosum Steud., Syn. Pl. Glumac. 1: 408. 1854. Erianthus saccharoides Michx. var. trinii Hack., Fl. Bras. 2(3): 258. 1883. Erianthus trinii (Hack.) Hack. in A. DC. \& C. DC., Monogr. Phan. 6: 135. 1889. Erianthus glabrinodis (Hack.) Swallen, Phytologia. 14(2): 93.1966. Erianthus purpureus Swallen, Phytologia 14(2): 92.1966. Erianthus clandestinus Swallen ex L.B. Sm., Wassh. \& R.M. Klein, Fl. Il. Catarin. 1165-1167. 1982. Saccharum trinii (Hack.) Renv., Kew Bull. 39(1): 184.1984.

Fig. 3 F-G

Distribui-se na Argentina, Paraguai e Brasil (Morrone et al. 2008). No Brasil ocorre nas regiões Nordeste, Sudeste e Sul (Filgueiras \& Lerina 2001b; Filgueiras 2010f). Na Ilha de Santa Catarina está presente em áreas alteradas como roças abandonadas, barrancos em beira de estrada e encostas, em solo geralmente úmido.

A espécie é reconhecida por apresentar espiguetas densamente pilosas e longas inflorescências que podem alcançar até $48 \mathrm{~cm}$ de comprimento, geralmente incluídas na espatéola lateralmente. Coletada com flor e/ou fruto de novembro a abril.

Material selecionado: BRASIL. Santa Catarina: Florianópolis, Saco Grande, Unidade de Conservação Desterro, 16/IV/2010, A. Zanin 1607 (FLOR).

9. Schizachyrium Nees, Agrost. Bras. in Martius, Fl. Bras. Enum. Pl. 2(1): 331-332. 1829.

Gênero com cerca de 60 espécies distribuídas em regiões tropicais e subtropicais do globo (Renvoize 1984; Clayton \& Renvoize 1986). Para América do Sul são reconhecidos 22 táxons, sendo dez endêmicos, e para o Brasil 15 espécies (Peichoto 2010). Na Ilha de Santa Catarina está representado por duas espécies, Schizachyrium glaziovii Peichoto e S. microstachyum (Desv. ex Ham.) Roseng., B.R. Arrill. \& Izag.
Chave de identificação das espécies de Schizachyrium ocorrentes na llha de Santa Catarina

1. Inflorescências lineares eretas ou nutantes, de $30-62 \mathrm{~cm}$ compr.; pedúnculo 3-6 $\mathrm{mm}$ compr.; gluma inferior da espigueta séssil de 5,6-6,8 mm compr.; espatéola 2,2-3,1 cm compr., geralmente convoluta apenas na base ................. 1. S. glaziovii

1. Inflorescências corimbiformes com até $25 \mathrm{~cm}$ compr.; pedúnculo (8-)10-15 mm compr.; gluma inferior da espigueta séssil alcançando 4-5 mm compr.; espatéola 1,4-2($2,1) \mathrm{cm}$ compr., geralmente convoluta em toda extensão 2.S. microstachyum

9.1 Schizachyrium glaziovii Peichoto, Candollea 65(2): 314. 2010.

Fig. $3 \mathrm{H}$

Espécie de ampla distribuição em quase toda a América do Sul, exceto no Chile, com distribuição em todas as Regiões do Brasil (Peichoto 2010). Na Ilha de Santa Catarina foi observada geralmente ocorrendo em simpatria com Schizachyrium microstachyum em áreas alteradas em geral, banhados, em solos arenosos úmidos de baixadas da restinga e gramados.

O material reconhecido na Ilha de Santa Catarina sob Schizachyrium glaziovii tem sido tradicionalmente tratado como S. microstachyum subsp. elongatum (Hack.) Roseng., B.R. Arrill. \& Izag. por Rosengurtt et al. $(1968,1970)$ e autores que o seguiram. Este nome foi incluído por Peichoto (2010) na sinonímia de S. spicatum (Spreng.) Herter. Schizachyrium glaziovii diferencia-se de S. microstachyum especialmente pelas características apresentadas na chave. Coletada com flor e/ou fruto durante todo o ano.

Material selecionado: BRASIL. Santa Catarina: Florianópolis, Ingleses, 08/I/2010, B. Toncic \& A. Zanin 297 (FLOR).

9.2 Schizachyrium microstachyum (Desv. ex Ham) Roseng., B.R. Arrill. \& Izag., Bol. Fac. Agron. Univ. Montevideo 103: 35. 1968. Andropogon microstachyus Desv. ex Ham., Prodr. Pl. Ind. Occid. 8-9. 1825.

Fig. 3 I-J

Schizachyrium microstachyum é uma das espécies do gênero mais presente na América do Sul, distribuindo-se na Argentina, Brasil, Bolívia, Colômbia, Equador, Guiana Francesa, Guiana, Peru, Paraguai, Suriname, Uruguai e Venezuela (Peichoto 2010). No Brasil ocorre em todas as regiões (Peichoto 2010). Na Ilha de Santa Catarina está presente em áreas alteradas em geral, banhados, em solos arenosos úmidos de baixadas da restinga e gramados. Coletada com flor e/ou fruto durante todo o ano.

Material selecionado: BRASIL. Santa Catarina: Florianópolis, Córrego Grande, 14/XI/2009, B. Toncic \& A. Zanin 244 (FLOR).

10. Sorghum Moench, Methodus: 207. 1794.

Gênero com cerca de 50 espécies de regiões tropicais e subtropicais (Nicora \& Rúgolo de Agrasar 1987; Longhi- 

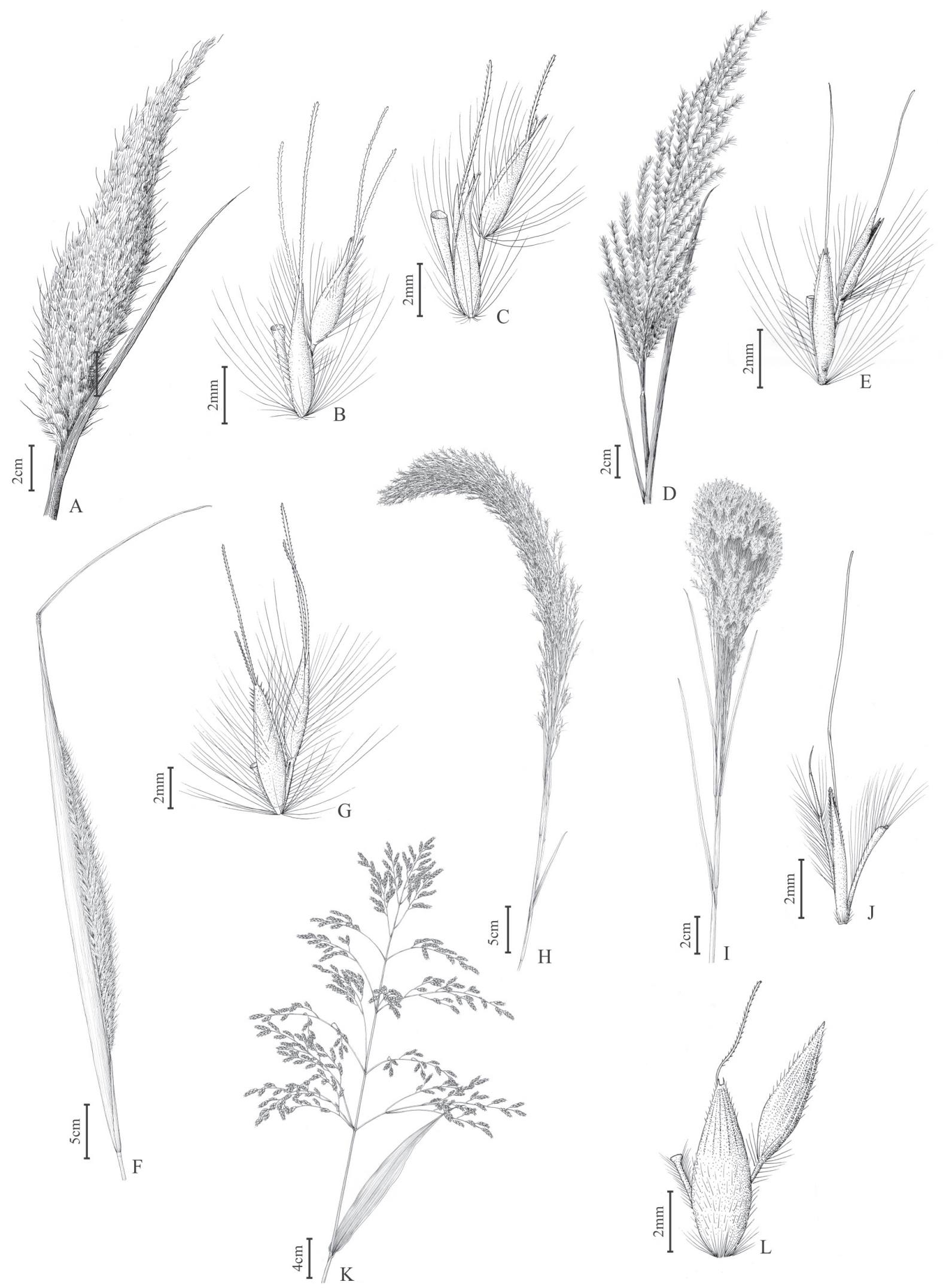

Figura 3. A-C. Saccharum angustifolium. A. Inflorescência, B. diásporo com espiguetas sésseis pilosas e com duas aristas, C. diásporo com espiguetas sésseis glabras e com uma arista (B. Toncic \& A. Zanin 278); D-E. S. asperum. D. inflorescência, E. par de espiguetas (B. Toncic \& A. Zanin 306); F-G. S. villosum. F. inflorescêcia, G. par de espiguetas (B. Toncic \& A. Zanin 279); H. Schizachirium glaziovii, inflorescência (A. Zanin \& Santos 1605); I-J. S. microstachyum. I. inflorescência, J. par de espiguetas (A. Zanin \& Santos 1604); K-L. Sorghum halepense. K. Inflorescência, L. par de espiguetas (B. Toncic \& A. Zanin 201). 
Wagner 2001c). No Brasil está representado por três espécies subespontâneas (Filgueiras 2010g). Na Ilha de Santa Catarina ocorre uma espécie.

10.1 Sorghum halepense (L.) Pers., Syn. Pl. 1: 101. 1805. Holcus halepensis L., Sp. Pl. 2: 1047-1048. 1753.

Fig. 3 K-L

Natural da região mediterrânea, introduzida e naturalizada em regiões tropicais e subtropicais (Renvoize 1998). Na América do Sul é conhecida para a Argentina, Chile, Paraguai, Uruguai e Brasil (Morrone et al. 2008). No Brasil está presente nas regiões Nordeste, Centro-Oeste, Sudeste e Sul (Filgueiras 2010g). Na Ilha de Santa Catarina foi encontrada ocorrendo espontaneamente em beira de estradas e terrenos baldios.

A espécie é reconhecida por suas longas inflorescências em panícula aberta, escabra ou esparsamente curto-pilosa, nós dos colmos pubescentes e região do colo geralmente violácea. Coletada com flor e/ou fruto durante todo o ano.

Material selecionado: BRASIL. Santa Catarina: Florianópolis, Carvoeira, 30/IV/2009, B. Toncic \& A. Zanin 201 (FLOR).

\section{Referências bibliográficas}

Allem, C.A. \& Valls, J.F.M. 1987. Recursos forrageiros nativos do Pantanal Mato-Grossense. Brasília, EMBRAPA-CENARGEN.

Brummitt, R.K. \& Powell, C.E. 1992. Authors of plant names. Kew, Royal Botanical Gardens.

Burman, A.G. 1985. Nature and composition of the grass flora of Brazil. Willdenowia 15: 211-233.

Caruso, M.M.L. 1990. O desmatamento da Ilha de Santa Catarina de 1500 aos dias atuais. 2 ed. Florianópolis, UFSC.

CECCA (Centros de Estudos Cultura e Cidadania). 1997. Unidades de Conservação e Áreas Protegidas da Ilha de Santa Catarina: caracterização e legislação. Florianópolis, Insular.

Clayton, W.D. \& Renvoize, S.A. 1982. Gramineae. Pp. 700-767. In: Polhill, R.M. (Ed.). Flora of Tropical East Africa. Rotterdam, Balkema. Part 3.

Clayton, W.D. \& Renvoize, S.A. 1986. Genera graminum: Grasses of the world. Her Magesty's Stationery Office, London, Kew Bulletin additional Series, 13.

Clayton, W.D., Harman, K.T. \& Williamson, H. 2006. Grass Base - The Online World Grass Flora. http: //www.kew.org/data/grasses-db. html. (Acesso em 20/01/2011).

Filgueiras, T.S. 2010a. Eriochrysis. In: Lista de Espécies da Flora do Brasil. Jardim Botânico do Rio de Janeiro. http: //floradobrasil.jbrj. gov.br/2010/FB013233 (Acesso em 25/01/2011).

Filgueiras, T.S. 2010b. Hyparrhenia. In: Lista de Espécies da Flora do Brasil. Jardim Botânico do Rio de Janeiro. http: //floradobrasil.jbrj. gov.br/2010/FB013270 (Acesso em 25/01/2011).

Filgueiras, T.S. 2010c. Imperata. In: Lista de Espécies da Flora do Brasil. Jardim Botânico do Rio de Janeiro. http: //floradobrasil.jbrj.gov. br/2010/FB013289 (Acesso em 25/01/2011).

Filgueiras, T.S. 2010d. Ischaemum. In: Lista de Espécies da Flora do Brasil. Jardim Botânico do Rio de Janeiro. http: //floradobrasil.jbrj. gov.br/2010/FB013293 (Acesso em 25/01/2011).

Filgueiras, T.S. 2010e. Rhytachne. In: Lista de Espécies da Flora do Brasil. Jardim Botânico do Rio de Janeiro. http: //floradobrasil.jbrj.gov. br/2010/FB013566 (Acesso em 25/01/2011).

Filgueiras, T.S. 2010f. Saccharum. In: Lista de Espécies da Flora do Brasil. Jardim Botânico do Rio de Janeiro. http: //floradobrasil.jbrj. gov.br/2010/FB013568 (Acesso em 25/01/2011).
Filgueiras, T.S. 2010g. Sorghum. In: Lista de Espécies da Flora do Brasil. Jardim Botânico do Rio de Janeiro. http: //floradobrasil.jbrj.gov. br/2010/FB087065 (Acesso em 25/01/2011).

Filgueiras, T.S. \& Lerina, R. 2001a. Eriochrysis. Pp. 101-102. In: LonghiWagner, H.M.; Brittrich, V.; Wanderley, M.G.L. \& Shepherd, G.J. (Eds.). Poaceae. Flora Fanerogâmica do Estado de São Paulo. Vol.1. São Paulo, Hucitec.

Filgueiras, T.S. \& Lerina, R. 2001b. Saccharum. Pp. 108-110. In: LonghiWagner, H.M.; Brittrich, V.; Wanderley, M.G.L. \& Shepherd, G.J. (Eds.). Poaceae. Flora Fanerogâmica do Estado de São Paulo. Vol.1. São Paulo, Hucitec.

Filgueiras, T.S., Longhi-Wagner, H.M., Viana, P.L., Zanin, A., Guglieri, A., Oliveira, R.C. de, Canto-Dorow, T.S. 2010. Poaceae. In: Lista de Espécies da Flora do Brasil. Jardim Botânico do Rio de Janeiro. http:// floradobrasil.jbrj.gov.br/2010/FB000193 (Acesso em 25/01/2011).

Flores, A.I.P. 2001a. Bothriochloa. Pp. 96-97. In: Longhi-Wagner, H.M.; Brittrich, V.; Wanderley, M.G.L. \& Shepherd, G.J. (Eds.). Poaceae. Flora Fanerogâmica do Estado de São Paulo. Vol.1. São Paulo, Hucitec.

Flores, A.I.P. 2001b. Imperata. Pp. 105-106. In: Longhi-Wagner, H.M.; Brittrich, V.; Wanderley, M. G.L. \& Shepherd, G.J. (Eds.). Poaceae. Flora Fanerogâmica do Estado de São Paulo. Vol.1. São Paulo, Hucitec.

Flores, A.I.P. 2001c. Ischaemum. Pp. 107. In: Longhi-Wagner, H.M.; Brittrich, V.; Wanderley, M.G.L. \& Shepherd, G.J. (Eds.). Poaceae. Flora Fanerogâmica do Estado de São Paulo. Vol.1. São Paulo, Hucitec.

GPWG (Grass Phylogeny Working Group). 2001. Phylogeny and subfamilial classification of grasses (Poaceae). Annals of the Missouri Botanical Garden 88: 373-457.

Hervé, A.M. \& Valls, J.F.M. 1980. O gênero Andropogon L. (Gramineae) no Rio Grande do Sul. Anuário Técnico do IPZFO 7: 317-410.

Hickey, M. \& King, C. 2000.The Cambridge illustrated glossary of botanical terms. Cambridge, Cambridge University Press.

Longhi-Wagner, H.M. 2001a. Hyparrhenia. Pp. 102-105. In: LonghiWagner, H.M.; Brittrich, V.; Wanderley, M.G.L. \& Shepherd, G.J. (Eds.). Poaceae. Flora Fanerogâmica do Estado de São Paulo. Vol. 1. São Paulo, Hucitec.

Longhi-Wagner, H.M. 2001b. Rhytachne. Pp. 108. In: Longhi-Wagner, H.M.; Brittrich, V.; Wanderley, M.G.L. \& Shepherd, G.J. (Eds.). Poaceae. Flora Fanerogâmica do Estado de São Paulo. Vol. 1. São Paulo, Hucitec.

Longhi-Wagner, H.M. 2001c. Sorghum. Pp. 114-118. In: Longhi-Wagner, H.M.; Brittrich, V.; Wanderley, M.G.L. \& Shepherd, G.J. (Eds.). Poaceae. Flora Fanerogâmica do Estado de São Paulo. Vol. 1. São Paulo, Hucitec.

Longhi-Wagner, H.M., Bittrich, V., Wanderley, M.G.L. \& Shepherd, G.M. (Eds.). 2001. Poaceae. Pp. 1-292. In: Wanderley, H.M.L.; Shepherd, G.J. \& Giulietti, A.M. (Coords). Flora fanerogâmica do estado de São Paulo. São Paulo, Hucitec.

Marchi, M.M. \& Longhi-Wagner, H.M. 1998. Gramineae - Andropogoneae: Gênero Bothriochloa Kuntze. Boletim do Instituto de Biociências 57: 1-99.

Mori, S.A.; Silva, L.A.M.; Lisboa, G. \& Coradin, L. 1989. Manual de Manejo de Herbário Fanerogâmico. Ilhéus, CEPLAC.

Morrone, O.; Zuloaga, F.O.; Longhi-Wagner, H.M.; Izaguirre, P.; Beyhaut, R.; Cialdella, A.M.; Giussani, L.; Denham, S.S.; Guglieri, A.; Boldrini, I.; Zanin, A.; Salariato, D. \& De Gennaro, D. 2008. Poaceae. Pp. 609967. In: Zuloaga, F.O.; Morrone, O. \& Belgrano, M.J. (Eds.). Catálogo de las Plantas Vasculares del Cono Sur (Argentina, Sur de Brasil, Chile, Paraguay y Uruguay). Vol. 1.Monographs in Systematic Botany from the Missouri Botanical Garden 107.

Nicora, E.G. \& Rúgolo de Agrasar, Z.E. 1987. Los géneros de gramíneas de America Austral. Buenos Aires, Hemisfério Sur.

Peichoto, M.C. 2010. Revisión taxonômica de las espécies del género Schizachyrium (Poaceae: Andropogoneae) de Sudamérica. Candollea 65(2): 301-346.

Radford, A.E.; Dickison, W.C.; Massey, J.R. \& Bell, C.R. 1974. Vascular plant systematics. New York, Harper \& Row Pub.

Rambo, B. 1984. Gramineae Riograndenses. Pesquisas 36: 1-191.

Renvoize, S.A. 1984. The grasses of Bahia. Kew, Royal Botanic Garden.

Renvoize, S.A. 1988. Hacthbach's Parana grasses. Kew, Royal Botanic Gardens. 
Renvoize, S.A. 1998. Gramineas de Bolívia. Kew, The Royal Botanic Gardens.

Rosengurtt, B.; Arrilaga de Maffei, B.R. \& Izaguirre de Artucio, P. 1968. Especies nuevas y notas taxonómicas de gramíneas en Uruguay y Paraguay. Las espécies afines a Schizachyrium condensatum de Uruguay y Paraguay. Boletín Facultad de Agronomía Montevideo 103: 25-41.

Rosengurtt, B.; Arrilaga de Maffei, B.R. \& Izaguirre de Artucio, P. 1970. Gramineas Uruguayas. Montevideo, Universidad de la República.

Sánchez-Ken, J.G.; Clark, L.G.; Kellogg, E.A. \& Kay, E.E. 2007. Reinstatement and emendation of subfamily Micrairoideae (Poaceae). Systematic Botany 32: 71-80.

Smith, L.B.; Wasshausen, D.C. \& Klein, R.M. 1982. Gramíneas. Pp. 9101407. In: Reitz, R. (Ed.). Flora Ilustrada Catarinense (Gram.). Itajaí, Herbário Barbosa Rodrigues.

Thiers, B. 2010. [continuously updated]. Index Herbariorum: A global directory of public herbaria and associated staff. New York Botanical Garden's Virtual Herbarium. http: //sweetgum.nybg.org/ih/ (Acesso em 27/01/2011).

Türpe, A.M. 1984. Revision of the South American species of Schizachyrium (Gramineae). Kew Bulletin 39(1): 169-178.
Valls, J.F. M. 2010. Bothriochloa. In: Lista de Espécies da Flora do Brasil Jardim Botânico do Rio de Janeiro. http: //floradobrasil.jbrj.gov. br/2010/FB013056 (Acesso em 27/01/2011).

Vega, A.S. 2000. Revisión taxonômica de las espécies americanas del gênero Bothriochloa (Poaceae: Panicoideae: Andropogoneae). Darwiniana 38(1-2): 127-186.

Watson, L. \& Dallwitz, M.J. 1992. The grass genera of the world Wallingford, C.A.B. Internacional.

Zanin, A. 2001. Revisão de Andropogon L. (Poaceae - Panicoideae Andropogoneae) no Brasil. Tese de doutorado, Universidade de São Paulo, São Paulo.

Zanin, A. 2006. Uma nova combinação em Andropogon L. (Poaceae Andropogoneae). Insula 35: 51-67.

Zanin, A. 2010a. Andropogon. In: Lista de Espécies da Flora do Brasil Jardim Botânico do Rio de Janeiro. http: //floradobrasil.jbrj.gov. br/2010/FB012955 (Acesso em 27/01/2011).

Zanin, A. \& Longhi-Wagner, H.M. 2006. Sinopse do gênero Andropogon L. (Poaceae-Andropogoneae) no Brasil. Revista Brasileira de Botânica 29(2): 289-299. 